\title{
Joining Behavior of Ceramics to Metal by Using Lead-bismate Heavy Metal Glass Frit
}

\author{
Jin Sam Choi ${ }^{\dagger}$ \\ School of Advanced Materials Engineering, University of Ulsan, Ulsan 680-749, Korea \\ (Received March 14, 2014; Revised June 11, 2014; Accepted June 16, 2014)

\section{중금속 창연산화납계 저온유리 분말을 이용한 세라믹스/금속의 접합거동} \\ 최 진 삼 ${ }^{\dagger}$ \\ 울산대학교 첨단소재공학부 \\ (2014년 3월 14일 접수 ; 2014년 6월 11일 수정 ; 2014년 6월 16일 채택)

\begin{abstract}
The joining behavior of forsterite ceramics to SUS304 alloy using $8 \mathrm{PbO}-78 \mathrm{Bi}_{2} \mathrm{O}_{3}-8 \mathrm{~B}_{2} \mathrm{O}_{3}-4 \mathrm{ZnO}-2 \mathrm{SiO}_{2}$ (wt $\%$ ) system glass frit was investigated. The contact angle was smaller than $90^{\circ}$ at a temperature of $460^{\circ} \mathrm{C}$. Redox reaction at the interface between forsterite and SUS304 was found to appear when the electrons in the metal part moved toward the glass part and the oxygen ions in glass moved to the metal side. The decrease of the surface tension due to the $\mathrm{PbO}$ solubility on the forsterite side contributed to the better wetting behavior at low temperature.
\end{abstract}

Key words : Forsterite, SUS304, Glass frit, Redox reaction, Solubility, Joining

\section{1. 서 론}

포스테라이트(forsterite, $\mathrm{Mg}_{2} \mathrm{SiO}_{4}$ )는 저유전손실과 고주 파 안정성이 우수해 전극의 격막재료로 활용된다. 그러나 $45 \mathrm{MgO}-55 \mathrm{SiO}_{2}(\mathrm{wt} \%)$ 의 조성을 가지는 포스테라이트는 $\mathrm{SiO}_{2}$ 와 $\mathrm{Al}_{2} \mathrm{O}_{3}$ 성분이 포함된 고온경질유리와의 접합계면에서 트리디마이트(tridymite, $\mathrm{SiO}_{2}$ )-프로토엔스테타이트(protoenstatite, $\mathrm{MgSiO}_{3}$ )-코디어라이트(cordierite, $2 \mathrm{MgO} \cdot 2 \mathrm{Al}_{2} \mathrm{O}_{3} \cdot 5 \mathrm{SiO}_{2}$ )상이 쉽게 형성된다고 알려져 있다. ${ }^{1)}$ 이는 $\mathrm{Al}_{2} \mathrm{O}_{3}-\mathrm{SiO}_{2}-\mathrm{RO}$ 계와 $\mathrm{B}_{2} \mathrm{O}_{3}-\mathrm{SiO}_{2}-\mathrm{R}_{2} \mathrm{O}$ 계 유리와 고온접촉 할 때 포스테라이트의 재분해로 인해서 국부적으로 $\mathrm{MgO}-\mathrm{Al}_{2} \mathrm{O}_{3}-\mathrm{SiO}_{2}$ 계를 형성하 여 $1350^{\circ} \mathrm{C}$ 부근에서 액상공융점이 나타나기 때문이다. ${ }^{2)}$ $\mathrm{B}_{2} \mathrm{O}_{3}-\mathrm{SiO}_{2}-\mathrm{Al}_{2} \mathrm{O}_{3}-\mathrm{Na}_{2} \mathrm{O}-\mathrm{RO}$ 계 또는 $\mathrm{SiO}_{2}-\mathrm{Al}_{2} \mathrm{O}_{3}-\mathrm{Na}_{2} \mathrm{O}-\mathrm{K}_{2} \mathrm{O}-$ $\mathrm{Li}_{2} \mathrm{O}(7056)$ 계 유리와 포스테라이트 접합에서 이에 관한 보 고가 있다. ${ }^{3,4)}$ 이러한 액상공융점은 자화(vitreous) 및 엔스 테타이트, 프로트엔스테타이트 그리고 실리카 매트릭스내 의 미립 뮬라이트(mullite, $3 \mathrm{Al}_{2} \mathrm{O}_{3} \cdot 2 \mathrm{SiO}_{2}$ ) 등의 혼합결정상 생성으로 전기절연성 저하가 나타난다고 보았다. ${ }^{2}$ 이는 포스테라이트를 이용하는 전기·전자모듈에서 $\mathrm{SiO}_{2}$ 와 $\mathrm{Al}_{2} \mathrm{O}_{3}$

${ }^{\dagger}$ Corresponding author : Jinsam Choi

E-mail : jmsamchoi@ulsan.ac.kr

Tel : +82-52-259-2722 Fax : +82-52-259-1688
성분을 포함하는 고온경질유리대신에 포스테라이트와 반 응성이 낮은 접합매개물에 관한 연구가 필요하다는 것을 의미한다.

최근 Choi등은 $\mathrm{Bi}_{2} \mathrm{O}_{3}-\mathrm{B}_{2} \mathrm{O}_{3}-\mathrm{ZnO}$ 계 유리로 $\mathrm{Ni}-\mathrm{Cr}$ 합금의 허메틱(hermatic) 밀봉과 $\mathrm{PbO}-\mathrm{B}_{2} \mathrm{O}_{3}-\mathrm{ZnO}$ 계의 나노스케일 유리분말에 $\mathrm{Pb}$ 금속필러를 혼합한 이종페이스트로 플립 칩(flip-chip)의 치밀한 저온접합 가능성을 보고하였다. ${ }^{5,6)}$

이런 관점에서 본 연구는 접합매개 유리조성에 $\mathrm{Al}_{2} \mathrm{O}_{3}$ 와 $\mathrm{SiO}_{2}$ 성분을 포함하지 않는 $\mathrm{PbO}-\mathrm{B}_{2} \mathrm{O}_{3}-\mathrm{ZnO}$ 계와 $\mathrm{Bi}_{2} \mathrm{O}_{3}$ $\mathrm{B}_{2} \mathrm{O}_{3}-\mathrm{ZnO}$ 계 유리조성을 조합한 $\mathrm{PbO}-\mathrm{Bi}_{2} \mathrm{O}_{3}-\mathrm{B}_{2} \mathrm{O}_{3}-\mathrm{ZnO}-\mathrm{SiO}_{2}$ 계 유리를 이용하여 포스테라이트와 스테인레스금속 $18 \% \mathrm{Cr}-$ $8 \% \mathrm{Ni}, \mathrm{SUS} 304)$ 기판간의 젓음성과 접합거동을 온도의 함 수로 고찰하였다.

\section{2. 실험 방법}

\section{1. 포스테라이트 시편제조}

탈크(talc) $50 \mathrm{~g}$ 과 $\mathrm{MgCO}_{3} 56.3 \mathrm{~g}$ (Samchun Chem. Co., Korea)을 볼밀에서 $48 \mathrm{~h}$ 건식 혼합한 후 $\mathrm{Al}_{2} \mathrm{O}_{3}$ 도가니에 담아 $1200,1300,1400,1550^{\circ} \mathrm{C}$ 에서 $2 \mathrm{~h}$ 동안 소결하였다. 이중 $1550^{\circ} \mathrm{C}$ 의 합성벌크 분쇄물에 결합제(P.V.E $3 \mathrm{wt} \%$ )를 첨가하고 몰드성형 후 $1450^{\circ} \mathrm{C}$ 에서 $1 \mathrm{~h}$ 동안 상압소결하 여 시편을 합성하였다. 


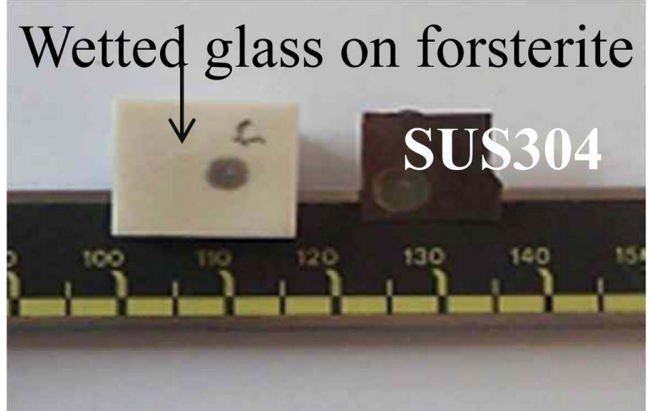

Fig. 1. Photo of a synthesized forsterite ceramic and SUS304 specimen.

\section{2. 접합매개유리 제조}

설계된 유리조성 $8 \mathrm{PbO}-78 \mathrm{Bi}_{2} \mathrm{O}_{3}-8 \mathrm{~B}_{2} \mathrm{O}_{3}-4 \mathrm{ZnO}-2 \mathrm{SiO}_{2}(\mathrm{wt} \%)$ 은 출발물질 $\mathrm{PbO}, \mathrm{Bi}_{2} \mathrm{O}_{3}, \mathrm{~B}_{2} \mathrm{O}_{3}, \mathrm{ZnO}$, 그리고 $\mathrm{SiO}_{2}$ (Junsei Chem. Co., Japan)을 무게별로 칭량하고 $12 \mathrm{~h}$ 건식 혼합한 후 $\mathrm{Al}_{2} \mathrm{O}_{3}$ 도가니에 담아 $750^{\circ} \mathrm{C}$ 에서 $20 \mathrm{~min}$ 동안 용융한 뒤, 고화한 유리를 볼밀로 분쇄하여 유리분말(glass frit)을 얻었다.

\section{3. 젖음성 및 접합거동}

Fig. 1 의 $15 \times 17 \mathrm{~mm}$ (가로 $\times$ 세로) 크기의 포스테라이트 시편과 SUS304 기판에 2.2절의 유리분말을 올린 후 온도 의 함수로 젖음과 접합을 평가하였다. 금속과 세라믹의 접합을 위하여 $10^{\circ} \mathrm{C}$ 간격으로 $440 \sim 500^{\circ} \mathrm{C}$ 의 구간에서 열 처리를 시도하였다. 열처리 조건은 $\mathrm{N}_{2}$ 분위기, 승온속도 $5^{\circ} \mathrm{C} / \mathrm{min}$, 그리고 유지시간은 $20 \mathrm{~min}$, 시편의 냉각은 노 냉을 하였다. 연구전체에 걸쳐 합성물의 결정상 $(\mathrm{XRD}, \mathrm{D} 8$ Advance, Bruker, USA), 유리전이온도(TG-DTA 8120, Rigaku, Japan), 젖음정도(평관현미경, LV100, Nikon, Japan), 그리 고 접합계면의 미세구조와 성분분석(SEM/EDS, JSM$6380 \mathrm{LV}$, Jeol, Japan) 등을 관찰하였다.

\section{3. 결과 및 고찰}

탈크를 이용한 합성결과를 나타낸 Fig. 2(a)에서 알 수 있듯이, 온도가 증가할수록 포스테라이트 $\left(\mathrm{Mg}_{2} \mathrm{SiO}_{4}\right)$ 가 주 결정상으로 나타났다. ${ }^{7)}$ Fig. 2(b)는 $\mathrm{PbO}-\mathrm{Bi}_{2} \mathrm{O}_{3}-\mathrm{B}_{2} \mathrm{O}_{3}-\mathrm{ZnO}$ 계 합성물의 결정상을 나타낸 것으로서 전형적인 비정질 의 XRD 패턴을 보이고 있다. 이는 2 차산화물로 분류되 는 $\mathrm{PbO}$ 와 $\mathrm{Bi}_{2} \mathrm{O}_{3}$ 를 $86 \mathrm{wt} \%$ 이상을 함유함에도 불구하고 냉각속도 조절을 통한 유리화가 가능하다는 기존의 연구 내용과 일치하였다. ${ }^{6)}$ 모유리의 $\mathrm{T}_{\mathrm{g}} / \mathrm{DTA}$ 거동을 관측한 Fig. 3을 보면, 유리전이온도 $\left(\mathrm{T}_{\mathrm{g}}\right)$ 는 $370^{\circ} \mathrm{C}$ 부근에서 나타 남을 알 수 있다.

Fig. 4는 식 (1)을 이용하여 포스테라이트, $\mathrm{PbO}-\mathrm{Bi}_{2} \mathrm{O}_{3}-\mathrm{B}_{2} \mathrm{O}_{3}$ $\mathrm{ZnO}$ 계 유리, 그리고 $\mathrm{SUS} 304$ 간의 젖음각을 나타내었다.

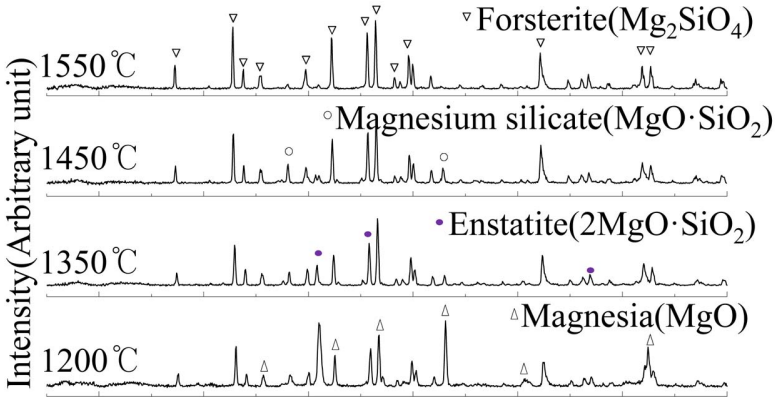

(a)

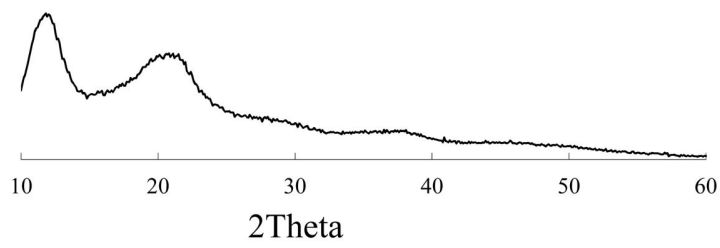

(b)

Fig. 2. XRD patterns of samples. (a) Forsterite synthesized a function of temperature and (b) $\mathrm{PbO}-\mathrm{Bi}_{2} \mathrm{O}_{3}-\mathrm{B}_{2} \mathrm{O}_{3}$ $\mathrm{ZnO}$ system glass frit.

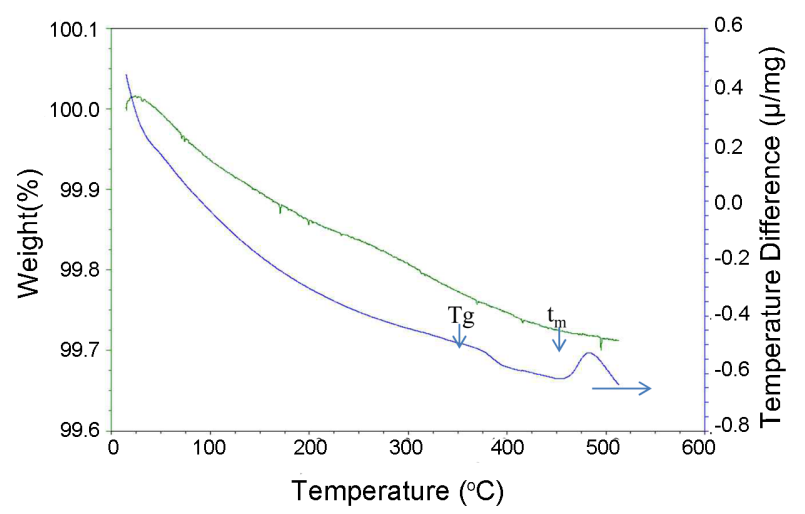

Fig. 3. $\mathrm{T}_{\mathrm{g}} / \mathrm{DTA}$ curves $\mathrm{PbO}-\mathrm{Bi}_{2} \mathrm{O}_{3}-\mathrm{B}_{2} \mathrm{O}_{3}-\mathrm{ZnO}$ glass system: $\mathrm{T}_{\mathrm{g}}$ and $\mathrm{t}_{\mathrm{m}}$ mean transition temperature and melting temperature, respectively.

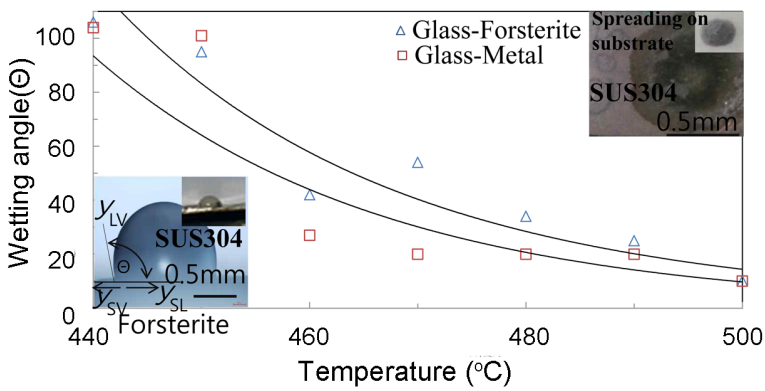

Fig. 4. Contact angle of glass-forsterite, and glass-metal interface and schematic diagrams of sessile drop configurations. (a) non-wetting drops; (b) and (c) wetting drops. The contact angle is identified as $\theta$. $440 \sim 500^{\circ} \mathrm{C}$ interval $10^{\circ} \mathrm{C}$ held for $20 \mathrm{~min}$ in a furnace containing $\mathrm{N}_{2}$. 
Table 1. Free Energy, $\Delta \mathrm{G}$, and the Standard Free Energy, $\Delta \mathrm{G}^{0}$ Changes for Several Reactions

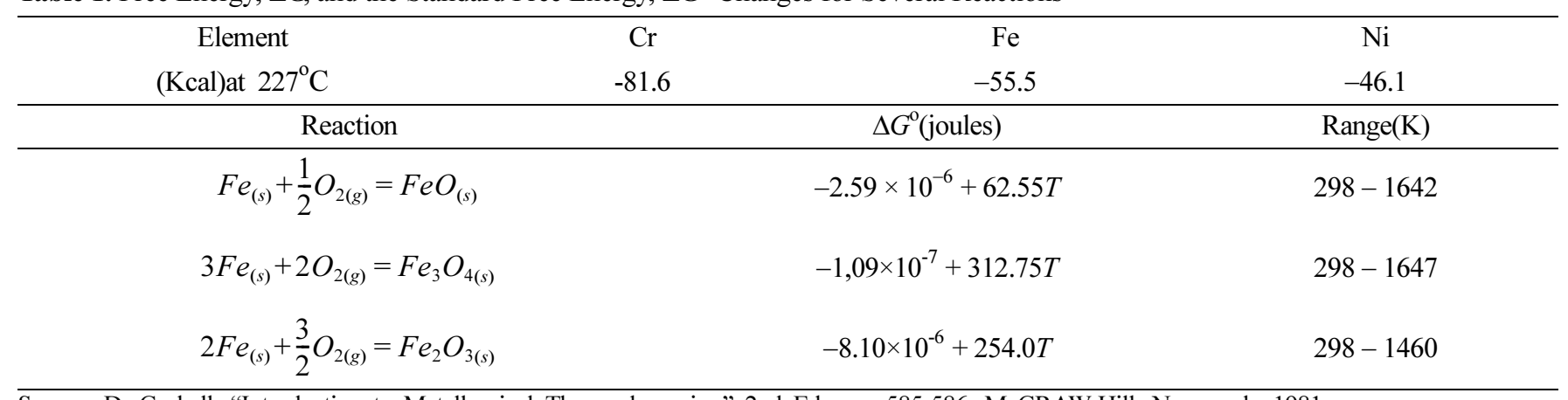

Source: D. Gaskell, "Introduction to Metallurgical Thermodynamics," 2nd Ed., pp. 585-586, McGRAW-Hill, New york, 1981

$$
\gamma_{S V}-\gamma_{S L}=\gamma_{L V} \cos \theta
$$

여기서 $\theta$ 는 액체와 고체표면의 접촉각, $\gamma_{L V}$ 는 액체-증기 계면 에너지, $\gamma_{S L}$ 는 고체-액체 계면 에너지, 그리고 $\gamma_{S V}$ 는 고체-증기 계면 에너지를 각각 나타낸다.

초기온도에서 젖음각은 $\theta<180^{\circ}$ 온도의 함수로 액체-증 기접촉각 변화에 따라 젖음과 퍼짐거동은 $450 \sim 460^{\circ} \mathrm{C}$ 범위에서 급격히 감소하는 경향을 보이고 있다. 이 각은 식 (1)에서 $\gamma_{S V}-\gamma_{S L}$ 와 $\gamma_{L V}$ 항의 증가 값에 의존한다. 이 값 은 결정내부에 비해 고에너지 상태인 계면의 원자이동, 표 면배열, 또는 불순물 흡착 등에 의한 자유에너지 변화에 의존하는 것으로 알려져 있다. ${ }^{8)}$ Table 1 은 $277^{\circ} \mathrm{C}$ 에서 $\mathrm{SUS} 304$ 구성성분 $\mathrm{Ni}, \mathrm{Cr}$ 과 $\mathrm{Fe}$ 의 자유에너지를 나타내었 다. 자유에너지 $(\Delta \mathrm{G})$, - 값을 가지므로 금속의 산화반응은 자발적으로 일어난다. 이중 $\mathrm{Fe}$ 는 $\mathrm{Fe}^{2+}$ 와 $\mathrm{Fe}^{3+}$ 로 $\mathrm{d}$ 각의 전 자빈자리(electron vacancy)를 먼저 채우는 전이금속 특징 때문에 식(2)와 (3)같은 산화반응이 예측된다. ${ }^{3,4,9)}$

$$
\begin{aligned}
& \mathrm{Fe}^{n+}+n e^{-}+4 \mathrm{Fe}_{2} \mathrm{O}_{3}=3 \mathrm{Fe}_{3} \mathrm{O}_{4} \\
& 2 \mathrm{Fe}^{3+}+6 e^{-}+(3 / 2) \mathrm{O}_{3}=\mathrm{Fe}_{2} \mathrm{O}_{3}
\end{aligned}
$$

위 산화반응이 일어나는 동안 금속표면의 변화거동은 다 음과 같이 예측된다. 먼저 $\mathrm{Fe}$ 이온은 $\mathrm{Fe}_{2} \mathrm{O}_{3}$ 또는 $\mathrm{Fe}_{3} \mathrm{O}_{4}$ 표 면 산소층을 통하여 확산이 일어난다.

이때 유리는 매우 큰 산소이온 이동도에 의한 표면배 열이 일어나고, 금속표면에 이동한 $\mathrm{Fe}$ 이온은 과잉으로 존재하는 산소이온의 흡착으로 금속표면의 계면에너지가 감소된다. 즉, 계면에서 금속은 전자를 유리쪽으로 내어 놓고 유리는 전자를 받아들이는 금속과 유리의 산화·환원 반응이 일어난다. 이러한 경향은 붕규산 유리-Kovar 계면 에서 $\mathrm{FeO}$ 산화층의 형성에서 확인되었다. ${ }^{3,9,10)}$ 그러나 이 산화층은 계면 에너지를 감소시켜 밀봉과 접합의 중심역 할은 상호일치 하지만 최적두께는 $0.3 \sim 0.7 \mathrm{mg} \cdot \mathrm{cm}^{-2}$ 로 연 구에 따라 차이가 있다. ${ }^{11,12)}$
유리, 금속, 그리고 포스테라이트 계면간의 미세구조와 성분분포를 $\mathrm{SEM} / \mathrm{EDS}$ 로 관찰한 Fig. 5 에서 알 수 있듯이, 금속-세라믹의 접합계면은 균열과 폐기공이 관찰되지 않 는 치밀한 접합형상을 보여주고 있다. SUS304와 유리계 면을 나타낸 Fig. 5(a)에서 $\mathrm{Pb}, \mathrm{Cr}, \mathrm{Bi}$ 원소 등 특정물질 의 풍부층(rich layer)을 보이고 있는 반면에, 포스테라이 트와의 계면에서의 성분분포는 $\mathrm{Pb}$ 와 $\mathrm{Bi}$ 원소가 상대적으 로 높게 나타났다. 유리-포스테라이트 계면의 성분분석 결 과를 나타낸 Fig. 5(b)에서는 $\mathrm{Mg}, \mathrm{Si}, \mathrm{Pb}, \mathrm{Bi}$ 가 계면에서 상대적인 풍부원소로 나타나고 있다. 이는 $500^{\circ} \mathrm{C}$ 에서 포 스테라이트 표면에 $\mathrm{PbO}$ 가 용질로 작용하여 표면장력의 급격한 감소가 나타나기 때문에 젖음거동의 요인으로 설 명이 가능하다. 실제로 $\mathrm{MgO}$ 표면 에너지와 산화납유리 의 표면장력은 $1000 \mathrm{erg} / \mathrm{cm}^{2}$ 와 $150 \mathrm{dyne} / \mathrm{cm}$ 로 6.7배 정도차 이는 계면에서 $\mathrm{PbO}$ 성분이 $\mathrm{MgO}$ 표면에 용질로 도입되면 급격한 표면장력의 감소가 나타난다. ${ }^{2)}$ 이 결과는 $\mathrm{MgO}$ 에 용해되는 $\mathrm{Al}_{2} \mathrm{O}_{3} \quad 100 \sim 150 \mathrm{ppm}$ 용질이 입계편석을 야기하 여 표면 에너지를 감소시키는 보고와 상응한다. ${ }^{13,14)}$

유리와 포스테라이트 계면에서의 성분분포는 $\mathrm{Pb}, \mathrm{Bi}$, $\mathrm{Si}, \mathrm{Mg}$ 원소가 상대적으로 높아 산화물간의 젖음은 미세 구조, 입계퍼텐셜, 공간전하, 그리고 불순물 등 복합요소 로 결정 ${ }^{2,4,14) ㄷ ㅚ ㄹ ~ ㅃ ㅜ ㄴ ㅁ ㅏ ㄴ ~ ㅇ ㅏ ㄴ ㅣ ㄹ ㅏ ~ F i g . ~ 5(b) ㅇ ㅢ ~ ㄱ ㅕ ㄹ ㄱ ㅘ ㄹ ㅗ ~ ㅂ ㅜ ㅌ ㅓ ~ ㅇ ㅛ ㅇ ㅈ ㅣ ㄹ ~}$ 에 의한 표면 에너지 변화를 고려하여 설명이 가능한 것 으로 나타났다.

$\mathrm{PbO}-\mathrm{Bi}_{2} \mathrm{O}_{3}-\mathrm{B}_{2} \mathrm{O}_{3}-\mathrm{ZnO}$ 계 유리 매개체를 이용하여 SUS304 의 표면산화와 용질에 의한 포스테라이트의 표면에너지 변화 결과들로부터 Fig. 6과 같은 저온접합기구를 도식화 하였다.

\section{4. 결 론}

탈크로부터 합성한 포스테라이트와 SUS304간의 접합 을 위하여, $\mathrm{PbO}-\mathrm{Bi}_{2} \mathrm{O}_{3}-\mathrm{B}_{2} \mathrm{O}_{3}-\mathrm{ZnO}$ 계 유리를 매개재로 이용 하고 그 젓음성과 계면반응거동을 관찰하였다. 젖음각 $\theta$ 

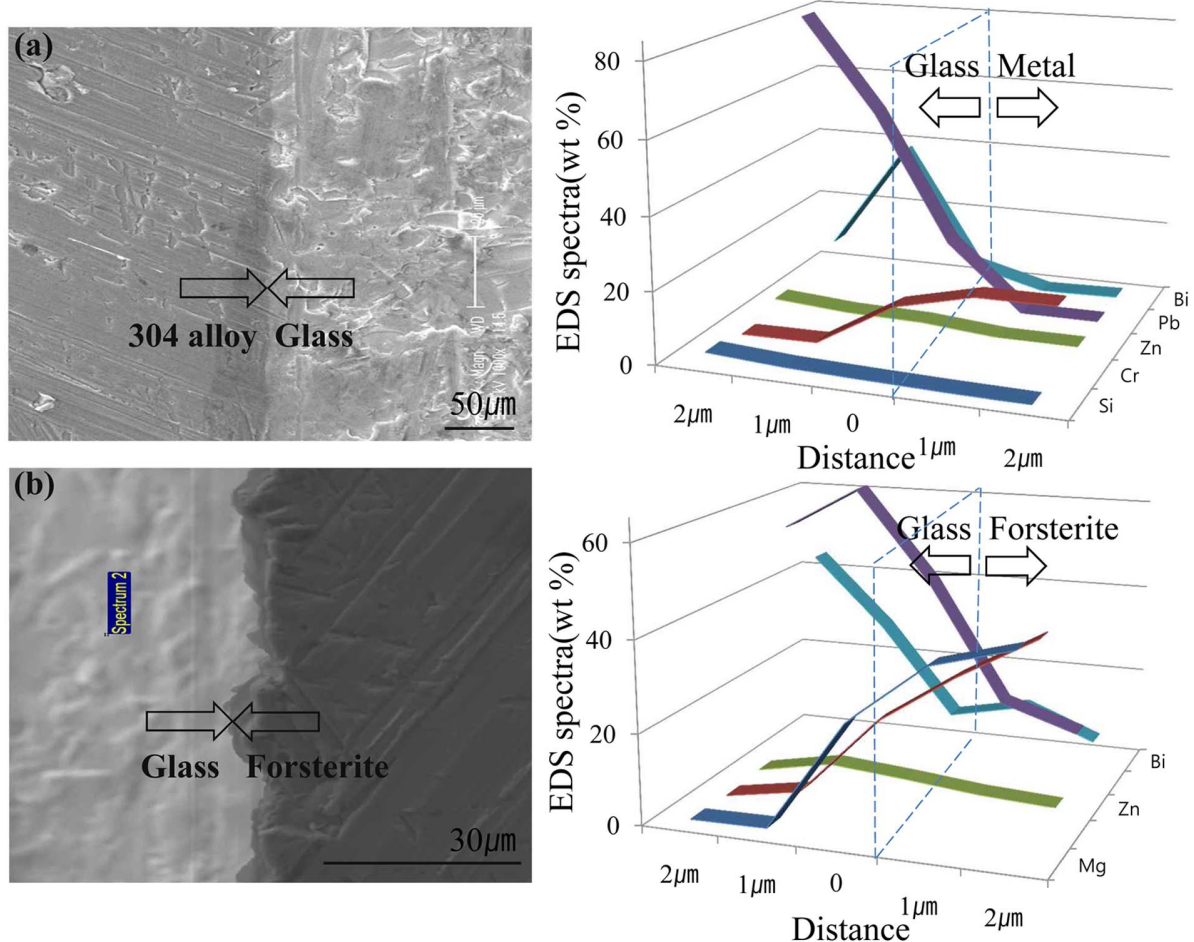

Fig. 5. Joining of SEM images and EDS results at the interface between (a) SUS304 to lead-bismmate glass and (b) Lead-bismate glass to forsterite.

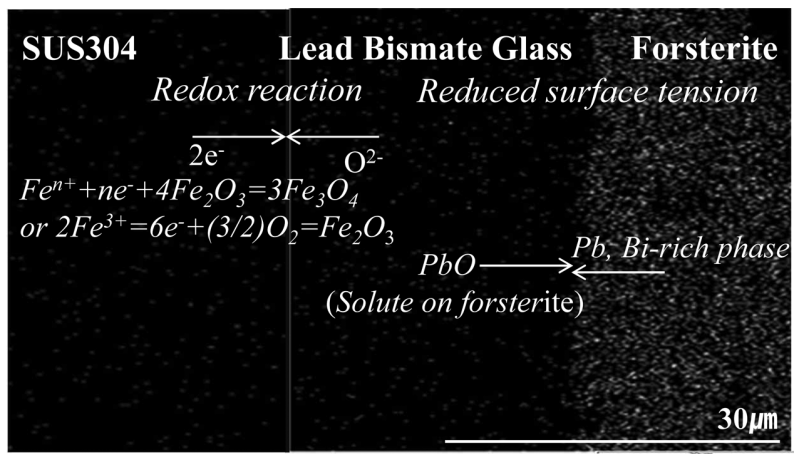

Fig. 6. Schematic joining behavior at interface of SUS3+4 and lead-bismate glass, and forsterite. Left side represents SUS304, middle is lead-bismate glass, and right side is forsterite from EDS image, respectively

는, 열처리 온도 $460^{\circ} \mathrm{C}$ 를 기점으로 $90^{\circ} \mathrm{C}$ 이하로 급격히 감소하며 $490^{\circ} \mathrm{C}$ 에서는 퍼짐거동이 관찰되었다. 유리-금속 계면에서 금속 측은 전자를 내어놓고 유리표면의 산소이 온은 금속으로 이동하는 산화·환원반응이 계면을 지배하 고, 유리-포스테라이트 계면에서 포스테라이트 측은 $\mathrm{PbO}$ 용질에 의해서 젓음거동을 나타내는 것으로 판단된다. 이 로 인해서 $\mathrm{PbO}-\mathrm{Bi}_{2} \mathrm{O}_{3}-\mathrm{B}_{2} \mathrm{O}_{3}-\mathrm{ZnO}$ 계 유리를 접합매개체로 적용할 경우 SUS304과 포스테라이트는 2차상의 생성 없 이 $500^{\circ} \mathrm{C}$ 이하의 저온영역에서 치밀한 접합이 가능한 것 으로 나타났다.

\section{REFERENCES}

1. A. G. M. Othman and N. M. Khalil, "Sintering of Magnesia Refractories though the Formation of Periclase-ForsteriteSpinel Phase," Ceram. Inter., 31 [8] 1117-21 (2005).

2. W. D. Kingery, H. K. Bowen, and D. R. Uhlmann, "Introduction to Ceramics," 2nd Ed. pp. 207-10 and pp. 304-11, John Wiley \& Sons, New Jersey, 1976.

3. C. Chanmung, M. Naksata, T. C. Chairuangsri, H. Jain, and C. E. Lyman, "Microscopy and Strength of Borosilicate Glass-to-Kovar Alloy Joints," Mater. Sci. Eng., A, 474 [1-2] 218-24 (2008).

4. T. S. Chern and H. L. Tsai, "Wetting and Sealing of Interface between 7056 Glass and Kovar Alloy," Mat. Chem. Phy., 104 [2-3] 472-78 (2007).

5. J. S. Choi, D. Y. Jeong, D. W. Shin, and W. T. Bae, "Characteristics of the $\mathrm{PbO}-\mathrm{Bi}_{2} \mathrm{O}_{3}-\mathrm{B}_{2} \mathrm{O}_{3}-\mathrm{ZnO}-\mathrm{SiO}_{2}$ Glass System Doped with $\mathrm{Pb}$ Metal Filler(in Korean)," J. Kor. Ceram. Soc., 50 [3] 238-43 (2013).

6. J. S. Choi, D. W. Shin, and W. T. Bae, "Effect of an Additive on the Physical and Electrical Properties of the $\mathrm{B}_{2} \mathrm{O}_{3}-\mathrm{Bi}_{2} \mathrm{O}_{3}$ $\mathrm{ZnO}$ Glass System for a Sheath Heater Module(in Korean)," J. Kor. Ceram. Soc., 50 [1] 57-62 (2013).

7. E. M. Levin, C. R. Robbins, and H. F. McMurdie, "Phase Diagrams for Ceramists," Am. Ceram. Soc., 1712 (1979).

8. W. D. Kingery, "Role of Surface Energies and Wetting in Metal-ceramics Sealing," Bull. Am. Ceram. Soc., 35 108-12 (1956).

9. A. Zanchetta, P. Lortholary, and P. Lefort, "Ceramic to Metal 
Sealing: Interfacial Reactions Mechanism in a PorcelainKovar Junction," J. All. Comp., 228 86-95(1995).

10. W. C. Wagner, K. Asgar, W. C. Bigelow, and R. A. Flinn, "Effect of Interfacial Variables on Metal-porcelain Bonding," J. Biomed. Mat. Res., 27 [4] 531-37 (1993).

11. C. E. Hoge, J. J. Brennan, and J. A. Pask, "Inerfacial Reaction and Wetting Behavior of Glass Iron System," J. Am. Ceram. Soc., 56 [2] 51-54 (1973).
12. J. A. Pask, "New Techniques in Glass-to-Metal Sealing," Proc. IRC, 36 [2] 286-89 (1948).

13. W. D. Kingery, "Role of Surface Energies and Wetting in Metal-ceramics Sealing," Bull. Am. Ceram. Soc., 35 108112 (1956).

14. W. Gąsior, Z. Moser, and J. Pstruś, "Density and Surface Tension of the Pb-Sn Liquid Alloys," J. Phas. Equ., 22 [1] 20-25 (2001). 